\title{
Seismic hazard assessment of Iran
}

\author{
Behrooz Tavakoli and Mohsen Ghafory-Ashtiany \\ International Institute of Earthquake Engineering and Seismology (IIEES), Tehran, I.R. Iran
}

\begin{abstract}
The development of the new seismic hazard map of Iran is based on probabilistic seismic hazard computation using the historical earthquakes data, geology, tectonics, fault activity and seismic source models in Iran. These maps have been prepared to indicate the earthquake hazard of Iran in the form of iso-acceleration contour lines, and seismic hazard zoning, by using current probabilistic procedures. They display the probabilistic estimates of Peak Ground Acceleration (PGA) for the return periods of 75 and 475 years. The maps have been divided into intervals of 0.25 degrees in both latitudinal and longitudinal directions to calculate the peak ground acceleration values at each grid point and draw the seismic hazard curves. The results presented in this study will provide the basis for the preparation of seismic risk maps, the estimation of earthquake insurance premiums, and the preliminary site evaluation of critical facilities.
\end{abstract}

Key words seismic hazard assessment - Iran earthquakes - historical seismicity - UN/IDNDR

\section{Introduction}

The probabilistic assessment of the seismic hazard in Iran involves specifying the likelihood, magnitude, location, and nature of earthquakes that might have damaging effect in the region or at the site and estimating the peak acceleration of the ground shaking. The basis for all seismic hazard assessment is the analysis of seismicity or the occurrence of earthquake in space and time. The term seismicity in this study has been used to describe different parts of earthquake record. These parts include: 1) the prehistorical and historical seismicity data (pre$1900) ; 2)$ the instrumental seismicity data (19001997), and 3) seismic sources of the historical and instrumental earthquakes, rate of activity,

\footnotetext{
Mailing address: Dr. Behrooz Tavakoli, International Institute of Earthquake Engineering and Seismology (IIEES), P.O. Box 19395/3913, Tehran, I.R. Iran; email: tavakoli@ dena.iiees.ac.ir
}

and fault interaction. Accurate knowledge of seismicity is an important tool for understanding active tectonics.

Seismic hazard analysis requires an assessment of the future earthquake potential in Iran. It is, therefore, necessary to estimate the maximum earthquake magnitude and recurrence character that might be generated by a particular active fault. The most common uses of more detailed geologic data have been to constrain maximum earthquake magnitudes using empirical relationships between earthquake rupture dimensions and magnitude.

One of the basic elements in assessing seismic hazards is to recognize seismic sources that could affect the particular location at which the hazard is being evaluated. These sources are often called seismotectonic sources. Defining and understanding seismotectonic sources is often the major part of a seismic hazard analysis and requires knowledge of the regional and local geology, seismicity, and tectonics. Two types of seismotectonic sources were identified in this study: fault or line sources, which may be sources of future earthquakes, and area sources, localizing structures and seismotectonic provinces. 
In this study, the geological and seismological data were integrated into a probabilistic seismic hazard model for Iran spanning the area between $25^{\circ}-40^{\circ} \mathrm{N}$ and $44^{\circ}-63^{\circ} \mathrm{E}$.

The main steps and parameters of the probabilistic seismic hazard assessment conducted in this study are summarized as follows:

1) Macroseismic, historical and instrumental seismic data that provided information on the regional stress and the location and frequency of earthquakes occurrence during the past several hundred years.

2) Seismic source model based on geological and seismological evidence; these sources describe the potential locations of future earthquakes within an area.

3) Source seismicity parameters estimating the recurrence relationships and the assessment of the maximum magnitude for each individual seismic source.

4) Attenuation of the strong ground motion providing information on the variation of ground motion levels with earthquake magnitude and source-to-site distance.

5) Recurrence forecasting which includes statistical methods used in the estimation of source seismicity information and stochastic model (Homogeneous Poisson Process) used in the estimation of seismic occurrences.

\section{Earthquake data base}

A review of Iran's historical earthquakes (pre1900) is provided by Ambraseys and Melville (1982). To improve the quality and accuracy of these earthquake data the new Earthquake Catalogue of Iran was compiled by Berberian in 1994. For the present century, the IIEES catalogue based on reports from international seismological institutes has been used.

With the inception of seismological stations, the location accuracy of the earthquakes has considerably improved since the mid 1960's. Thus, especially for Iran, it can be stated that a reliable earthquake database has existed only for the last few decades. Both of these catalogues have provided a base for the spatial correlation of the seismicity with the seismotectonic sources in Iran.
From 1930 to 1985 , the seismicity analysis of Iran was conducted by Wilson (1930), Niazi and Basford (1968), Nowroozi (1971, 1976), Banisadr (1971), Ambraseys and Moinfar (1973), Berberian (1973) and Tchalenko (1975). It is now agreed by several investigators that the seismicity in Iran is related to the local surface geology and tectonics. Many destructive earthquakes in the last century confirm this phenomenon: Silakhor $\left(M_{S}=7.4,1909\right)$; Salmas $\left(M_{S}=7.4\right.$, 1930); Torud $\left(M_{S}=6.4,1953\right)$; Lar $\left(M_{S}=6.7\right.$, 1960); Buyin Zahra $\left(M_{s}=7.2,1962\right)$; Dasht-eBayaz $\left(M_{S}=7.4,1968\right)$; Qir $\left(M_{S}=6.9,1972\right)$; Khorgu $\left(M_{S}=7,1977\right)$; Tabas $\left(M_{S}=7.7,1978\right)$; Qayen $\left(M_{S}=7.1,1979\right)$; Rudbar-Manjil $\left(M_{S}=7.2\right.$, 1990) and Birjand $\left(M_{S}=7.3,1997\right.$. The Iranian plateau is one of the seismically active areas of the world and frequently suffers destructive and catastrophic earthquakes that cause heavy loss of human life and widespread damage. Figure 1 maps the recent seismicity of Iran, showing the high inhomogeneity and dispersion of the seismic activity in the Iranian plateau. No earthquakes larger than $M_{s}=7.0$ have occurred in the Zagros region during the 20th century, but shocks of magnitude over $M_{s}=7.0$ have occurred in Central and Eastern Iran.

\section{Seismotectonic provinces of Iran}

The Iranian plateau can be characterized by active faults, recent volcanic and high surface elevation along the Alpine earthquake belt. Tectonic studies indicate that the Iranian plateau has a very high density of active and recent faults. Earthquake data show that most activity is concentrated along the Zagros fold thrust belt while less activity is observed in Central and Eastern Iran. Thus, several regions are vulnerable to destructive earthquakes. The preparation of an earthquake hazard map requires the delineation of the seismotectonic province and the assessment of the associated maximum earthquake potentials. They can be defined as a geographic region of some geological, geophysical and seismological similarity with the assumption of uniform earthquake potential. Earthquakes are assumed to occur randomly throughout the seismotectonic provinces event 


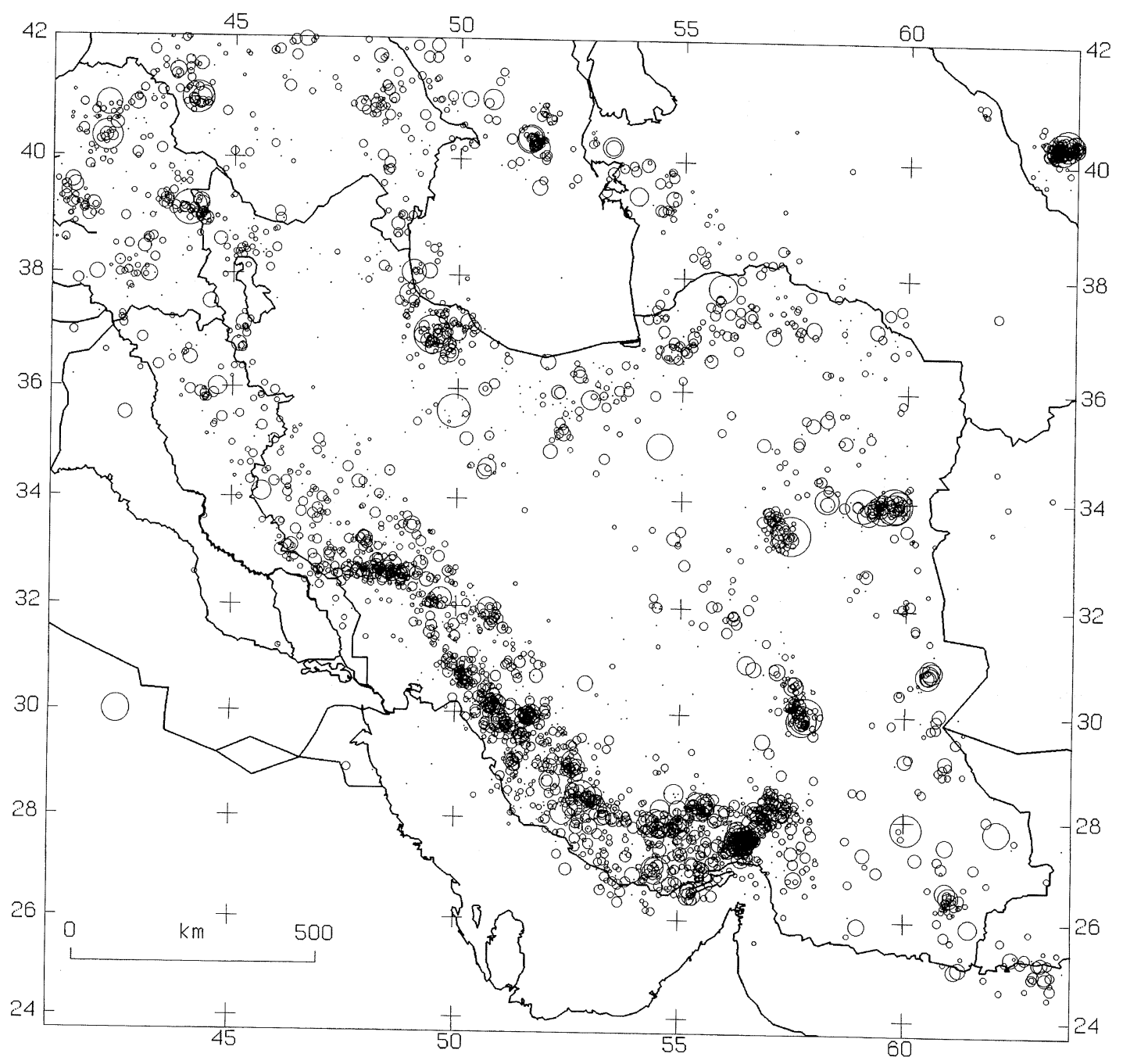

Fig. 1. Recent seismicity of Iran (IIEES catalogue).

though the earthquake record may indicate some clustering at preferred locations. The seismotectonic provinces of Iran are then defined as areas bounded by geological features which mark a difference in seismic characteristics of one province from its neighboring provinces. Each province has equal seismic potential and uniform geological structure and trends.
The seismotectonic structure of Iran was studied by several investigators in the past. Stocklin (1968), Takin (1972), and Berberian (1976) have suggested simplified divisions consisting of only nine, four, and four regions, respectively. A more elaborated division, consisting of twenty-three seismotectonic provinces was suggested by Nowroozi (1976). In the present work, a modified and updated catalogue of large and damag- 
ing Iranian earthquakes has been prepared to provide a basis for the correlation between seismic activity and seismotectonic provinces. On this basis, a new model of seismotectonic provinces has been proposed by Tavakoli (1996).

The boundaries of the provinces are established through analysis of seismic history, relocated epicenter for the past several decades, tectonic environments, active faults, regional geomorphology, and plate boundaries. Tavakoli (1996) divided Iran into 20 seismotectonic provinces, shown in fig. 2 . The known active faults of Iran are located within these twenty seismotectonic provinces.

\section{Earthquake hazard parameters}

Earthquake hazard analysis requires the assessment of earthquake hazard parameters such as the maximum expected magnitude, $M_{\max }$, the activity rate, $\lambda$, and the $b$ value of the Gutenberg-Richter relation. These parameters have been evaluated for each seismotectonic prov-

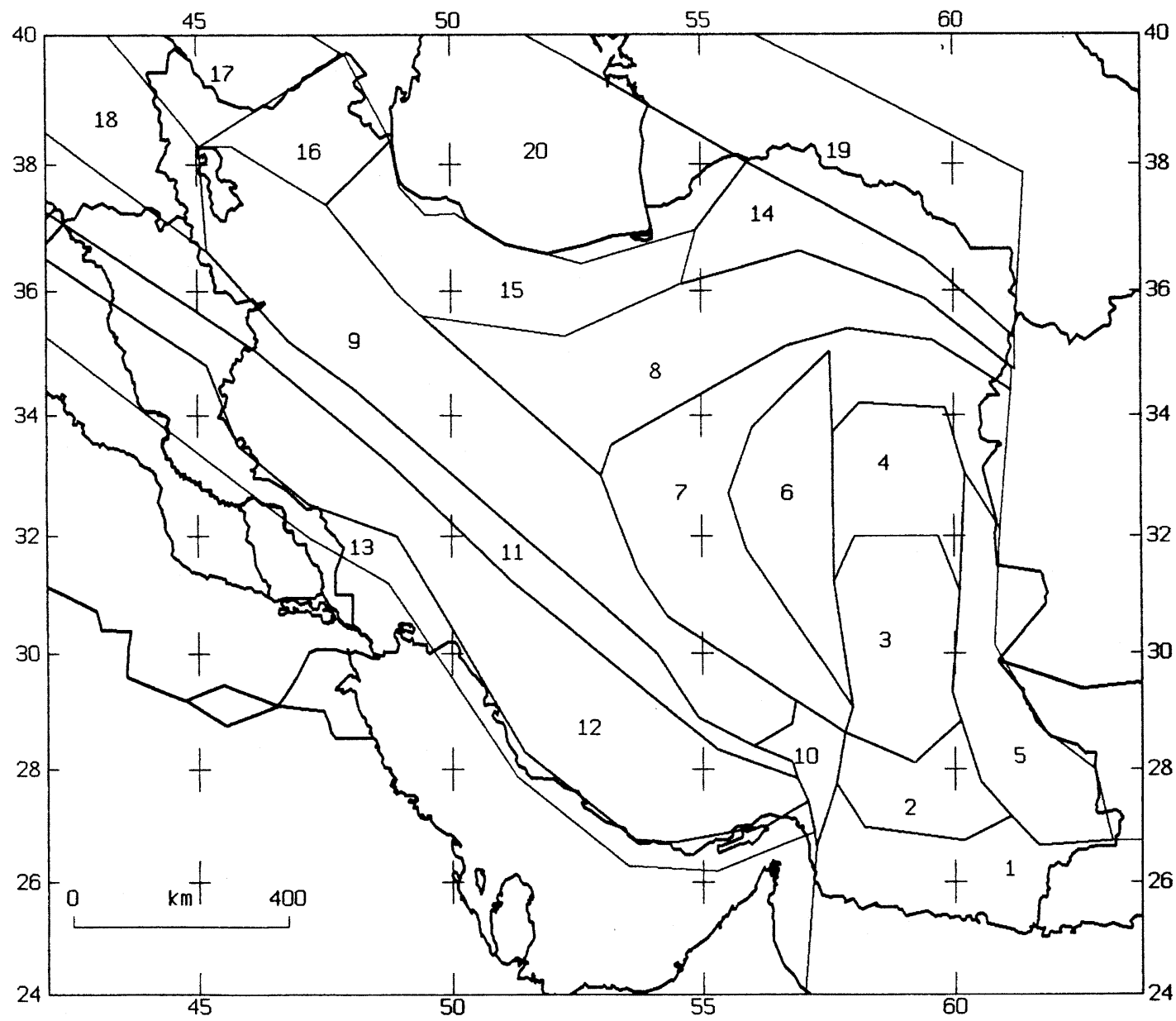

Fig. 2. Seismotectonic Provinces of Iran. 


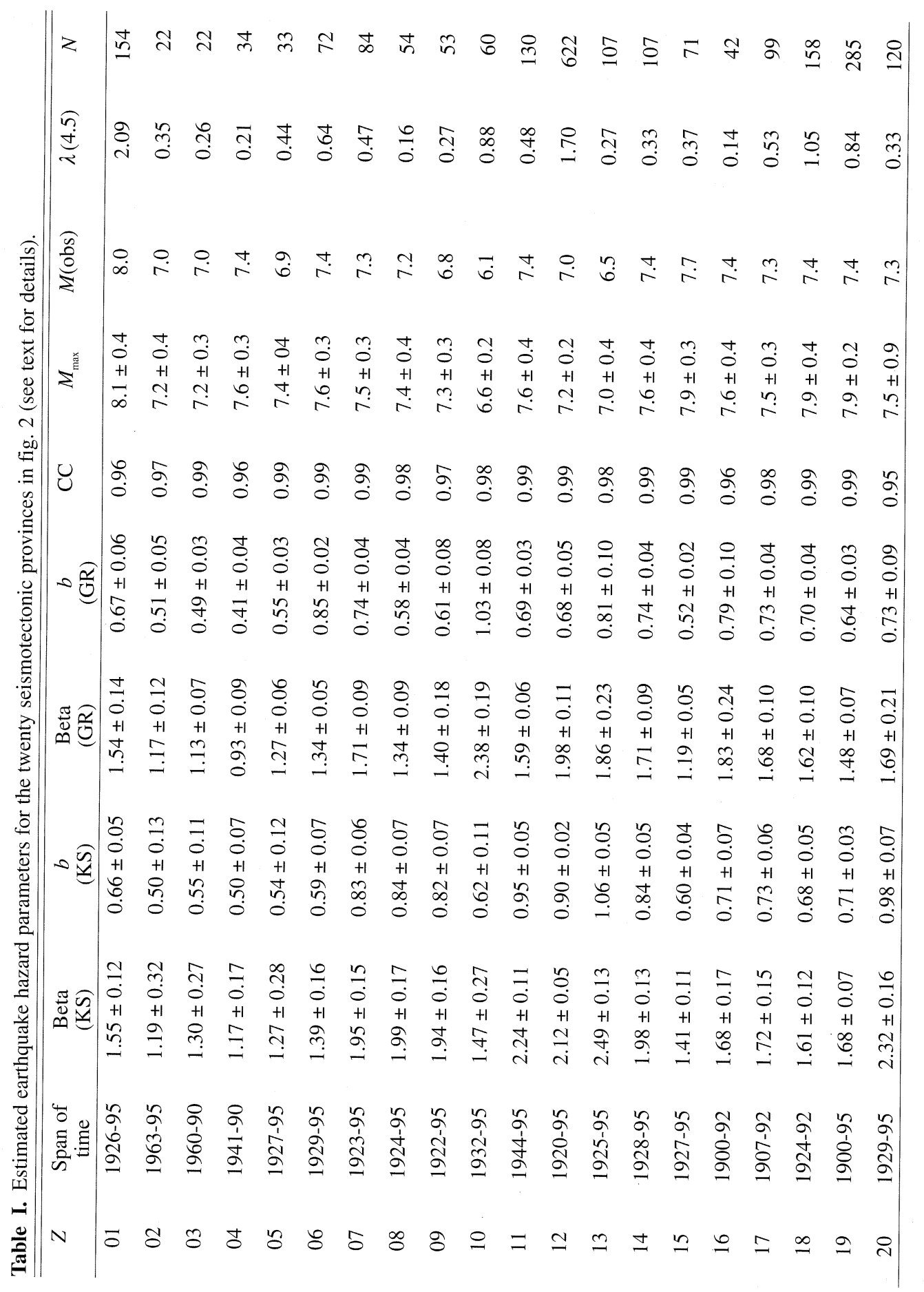


ince of Iran. In this study we applied the maximum likelihood method (Kijko and Sellevoll, 1992), allowing the combination of both historical and instrumental data. The maximum likelihood estimation of the seismicity parameter $b$ adapts well to the Iranian earthquake data, due to the fact that earthquake magnitudes have always been reported with associated uncertainty. In this method, artificially homogeneous data are also simulated, through the determination of the completeness period over which data in a given time span were reported. In the present study, unlike previous works for Iran, seismic gaps (i.e. when records are missing or the seismic network was not in operation) and uncertainties of earthquake magnitudes are considered in analysis. This is necessary for a region like Iran where few earthquake data are available. In this work, the Gutenberg-Richter parameters was assumed to be constant for each province.

The earthquake hazard parameters estimated for each seismotectonic province of Iran are shown in table I.

\section{Attenuation relationships}

Magnitude, distance and site conditions are the principal variables used in predicting future ground motions. A number of predictive relationships derived from regression analysis of strong motion data are available for peak horizontal ground acceleration.

The analysis requires a seismic source model of the region and appropriate attenuation relationships. It was decided to use the Campbell (1990) and Campbell-Bozorgnia (1993) attenuation relationships in this study. These relationships were derived empirically from recorded accelerograms produced by earthquakes in different parts of the world, mostly recorded in Western North America but also in other regions, including the Tabas and Manjil earthquake in Iran. However, Chandra et al. (1979) showed that the attenuation of acceleration is more rapid in Iran than Western North America. Therefore, the use of these relationships may be conservative. Zare, Bard and Ghafory-Ashtiany are developing a new attenuation law for Iran based on a new corrected strong-motion database. This however was not ready to be used for this hazard assessment. Therefore, the relationships quoted above have been accepted as appropriate models for evaluation of the ground motion parameters in this seismic zonation study.

\section{Approach and results of hazard analysis}

For probabilistic seismic hazard assessment SEISRISK III (a computer program for seismic hazard estimation) was used to calculate peak ground acceleration. The calculated values for earthquake hazard are displayed as iso-acceleration contours expected to be exceeded during typical economic lifetime of structures. This program is based on the assumption that the site acceleration has a Poisson distribution with a mean annual rate. The program can accommodate any attenuation relationships in digitized format and generate a table of peak ground accelerations and the cumulative distribution of the acceleration for each specified site. It is also capable of modeling acceleration variability and permits the option of earthquake location uncertainty, as well as smooth variation of seismicity across the boundaries of the zone.

Probabilistic ground motion analysis were made for sites located throughout the region on a $0.25^{\circ} \times 0.25^{\circ}$ grid and drawing seismic hazard curves. Figure 3 shows the iso-acceleration lines for the return periods of 75 and 475 years. Figure 4 shows the seismic hazard zones of Iran; four zone levels were defined, rated as: very high hazard, high hazard, moderate hazard and low hazard.

\section{Conclusions}

Seismic hazard maps have been prepared to indicate the earthquake hazard of Iran in the forms of iso-acceleration contour lines, and seismic hazard zonation. These maps were originally presented on 1: 5000000 scale. Characteristic of these maps are as follows:

1) The contour levels of the acceleration hazard maps range from $15 \%$ to $48 \% \mathrm{~g}$. 
2) The highest acceleration contours encompass the North Tabriz fault zone, North of Tehran, the Dasht-e-Bayaz fault zone, etc. The maximum mean acceleration in the vicinity of these tectonic elements is predicted to be around $0.45 \mathrm{~g}$ for a return period of 475 years and $0.30 \mathrm{~g}$ for a return period of 75 years.

3) The smallest accelerations are expected in two regions. One includes a narrow band trending NW-SE and extending from Urumiyeh to Esfahan; the other in the Central Lut zone in
Eastern Iran. Corresponding maximum acceleration values for both of these regions are less than $0.20 \mathrm{~g}$, and $0.35 \mathrm{~g}$ for return periods of 75 and 475 years, respectively.

4) The peak ground acceleration attenuation relationships considered in this study are given for the mean maximum horizontal acceleration in bedrock. In soil deposits of significant depth, the ground accelerations will be larger than those indicated on these hazard maps.

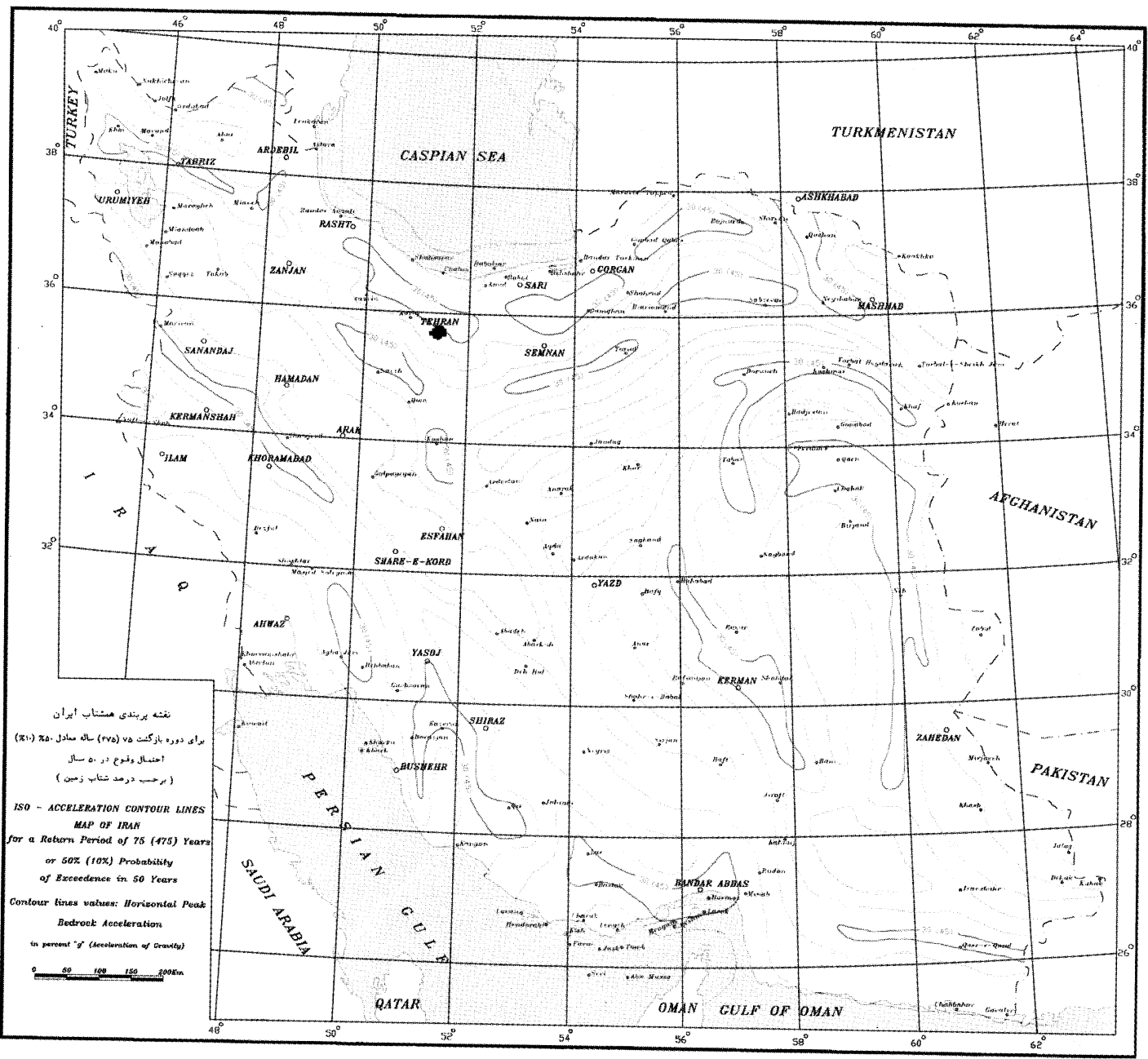

Fig. 3. Iso-acceleration lines (PGA) for return periods of 75 and 475 years. 


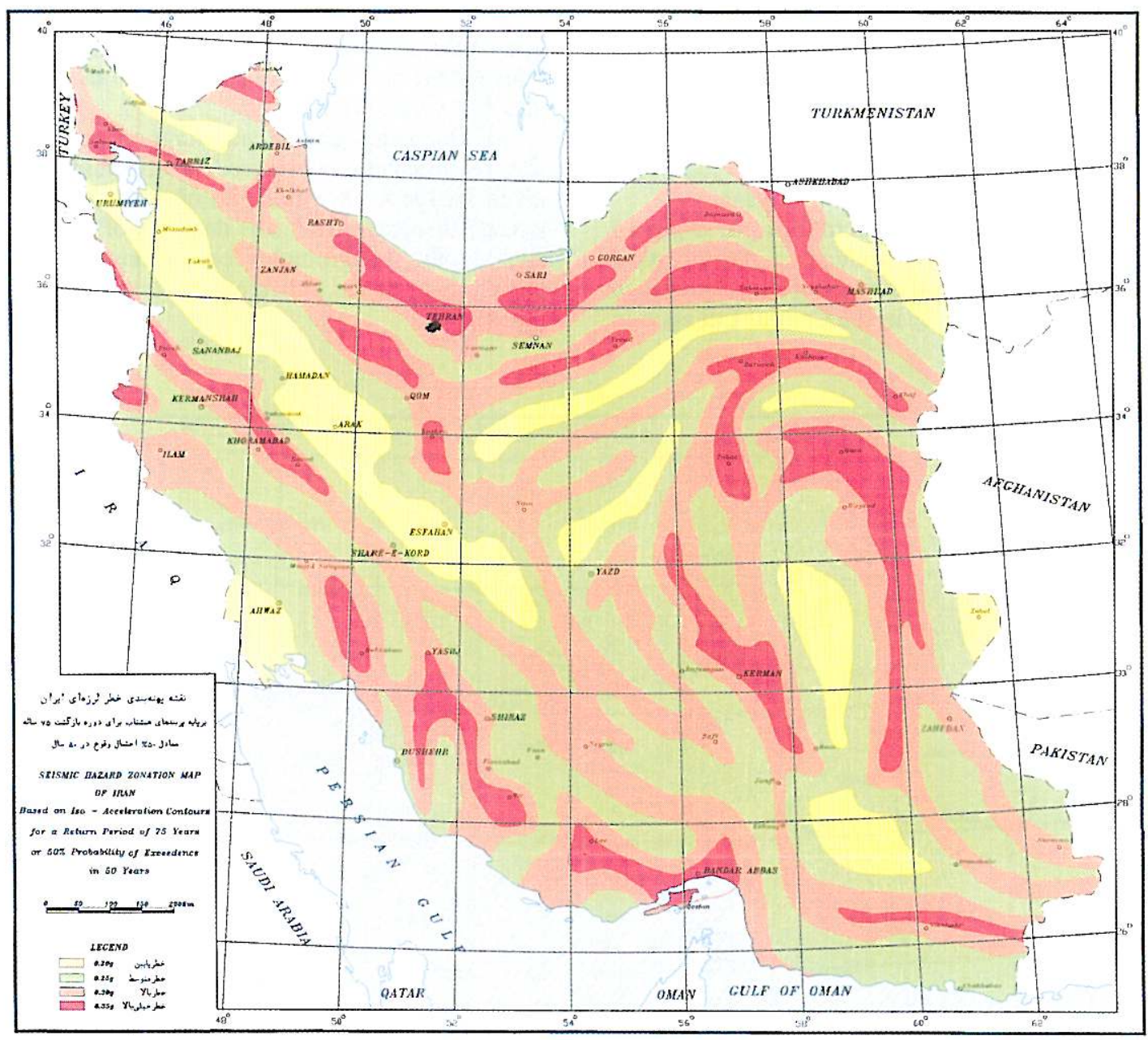

Fig. 4. Seismic hazard zoning of Iran; four zone levels are defined, rated as: very high hazard, high hazard, moderate hazard and low hazard.

5) The maps are intended for the assessment of the seismic hazard for engineering structures. Moreover, they may also be used for other purposes such as the preparation of seismic risk maps, the estimation of earthquake insurance premiums, and the preliminary site evaluation of critical facilities.

6) Since only major known sources have been considered in the preparation of these maps, it is recommended that for important type of structures, site specific studies which require deterministic hazard investigations, and identified local seismic sources on large scale maps be performed.

\section{REFERENCES}

Ambraseys, N.N. and C.P. MElVill. (1982): A History of Persian Earthquakes (Cambridge University Press, London), pp. 219. 
Ambraseys, N.N. and A.A. Moinfar (1973): The seismicity of Iran, The Silkhor, Lurestan, Earthquake of 23rd January 1909, Ann. Geofis., 4, 659-678.

BANISADR, M. (1971): The Seismicity of Iran (1900-1969), Plan Organization of the Government of Iran, Technical Research and Standard Bureau.

BENDER, B. and D.M. PERKINS (1987): SEISRISK III. A computer program for seismic hazard estimation, U.S. Geological Survey, Bulletin 1772.

Berberian, M. (1973): Prelimanary Map of Epicenters and Focal Depth, Geological Survery of Iran.

Berberian, M. (1976): Contribution to the Seismotectonic of Iran (Part II), Geol. Sur. of Iran, Rep. No. 39, p. 570.

BERBERIAN, M. (1994): Natural hazards and the first earthquake catalogue of Iran, International Institute of Earthquake Engineering and Seismology (IIEES), vol. 1, p. 620.

CAMPBELL, K.W. (1990): Rock ground motion for the Diable Canyon plant site, San Luis obispo country, California, Report Prepared for Lawrence Livermore National Laboratory by Dames and Moore (Job No. 10805-476-166).

CAMPBELL, K.W. and Y. Bozorgnia (1994): Near source attenuation of peak horizontal acceleration from worldwide accelerograms recorded form 1957 to 1993, in Proceedings Fifth U.S. National Conference of Earthquake Engineering (EERI), Berkeley, California, vol. 1, 283-292.
Chandra, V., J.G. MCWhorter and A.A. Nowroozi (1979): Attenuation of intensities in Iran, Bull. Seismol. Soc. Am., 69, 237-250.

KiJKo, A. and M.A. Selevoll (1992): Estimation of earthquake hazard parameters from incomplete data files. Part II. Incorporation of magnitude heterogeneity, Bull. Seismol. Soc. Am., 82, 120-134.

NIAZI, M. and J.R. BASFORD (1968): Seismicity of Iranian plateau and Hindu Kush region, Bull. Seismol. Soc. Am, 58, 1843-1861.

NowroozI, A. (1971): Seismotectonic of the Persian Plateau, Eastern Turkey, Caucasus and Hindu-Kush Region, Bull. Seismol. Soc. Am., 61 (2), 317-341.

NowroOzI, A. (1976): Seismotectonic Provinces of Iran, Bull. Seismol. Soc. Am., 66, 1249-1276.

STOCKLiN, J. (1968): Structural history and tectonics of Iran, a review, Bull. Am. Assoc. Petrol. Geol., 52, 12291258.

TAKIN, M. (1972): Iranian geology and continental drift in the Middle East, Nature, 235, (5334), 147-150.

TAVAKoli, B. (1996): Major Seismotectonic Provinces of Iran, unpublished map, IIEES, internal document.

TCHALENKO, J.S. (1975): Seismicity and structure of the North Tehran fault, Tectonophysics, 29, 411-420.

Wilson, A.T. (1930): Earthquakes in Persia, Bull. Sch. Orient. Stud., London, 6, 103-131. 